\title{
Distribution characteristics of star ratings in online consumer reviews
}

\section{6}

Received 18 October 2020 Revised 13 November 2020 Accepted 27 November 2020

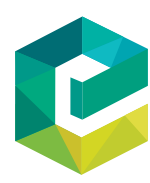

Vilakshan - XIMB Journal of Management Vol. 18 No. 2, 2021 pp. 156-170 Emerald Publishing Limited 0973-1954

DOI 10.1108/XJM-10-2020-0171
R. Venkatesakumar, Sudhakar Vijayakumar and S. Riasudeen Department of Management Studies, Pondicherry University, Pondicherry, India

\author{
S. Madhavan \\ Department of Management Studies, Manonmaniam Sundaranar University, \\ Tirunelveli, India, and \\ B. Rajeswari \\ Department of Management Studies, Pondicherry University, Pondicherry, India
}

\begin{abstract}
Purpose - The star rating summarises the review content and conveys the message faster than other review components. Star ratings influence helpfulness of the reviews, and extreme reviews are considered as less helpful in the decision process. However, literature has rarely addressed variations in star ratings across product categories and variations between two online retailers. In this paper, the authors have compared the distribution of star ratings across 11 products and among the retailers.

Design/methodology/approach - Online reviews for 11 product categories have collected, and the authors compared the distribution of star ratings across 11 products and retailers. Correspondence analysis has been applied to show the association between star ratings and product categories for the e-retail firms.

Findings - The Amazon site contains proportionately more number of 1-star rated reviews than Flipkart. In Amazon reviews, few product categories are closely associated with 1-star and 2-star reviews, whereas no product categories are closely associated with 1-star and 2-star reviews in Flipkart reviews. The results indicate two distinct communication strategies followed by the firms in managing online consumer reviews.

Research limitations/implications - The authors did not analyse data across demographic details because of access restriction policies of the websites.

Practical implications - Understanding the distribution of review characteristics will improve the consumer's decision-making ability and using online review content judiciously.

Social implications - This study's results show significant insights on online retailing by providing cues in using shopping sites and online review characteristics of two prominent retailers.

Originality/value - This paper has brought out a distinct distribution pattern of online review between Amazon and Flipkart. Amazon allows a higher degree of negative contents, whereas Flipkart allows more number of positive reviews.
\end{abstract}

Keywords Star rating, Online reviews, Cues, Signals, eWOM, Distribution

Paper type Research paper

(C) R. Venkatesakumar, Sudhakar Vijayakumar, S. Riasudeen, S. Madhavan and B. Rajeswari. Published in Vilakshan - XIMB Journal of Management. Published by Emerald Publishing Limited. This article is published under the Creative Commons Attribution (CC BY 4.0) licence. Anyone may reproduce, distribute, translate and create derivative works of this article (for both commercial and non-commercial purposes), subject to full attribution to the original publication and authors. The full terms of this licence maybe seen at http://creativecommons.org/licences/by/4.0/legalcode 


\section{Introduction}

Managing online source of communication is an important activity for electronic retailers (e-retailers) and service providers (e-services). It has become a customary practice in the consumer engagement strategy to provide an opportunity to consumers, to express their views. Feedback forms in product and service sites allow consumers to register their views and post-purchase evaluations. In recent years, firms take a step ahead and create social media handles and product or brand-specific blogs, to engage consumers in online platforms. It is a million-dollar question, and the answer keeps changing with time - how to manage online consumer communications and consumer reviews.

Online buying is subject to, ease of using the website, operate it comfortably and understand the website features quickly (Hasbullah et al., 2016). In the buying process, online reviews facilitate consumers to learn product quality, service satisfaction and overall customer satisfaction from other users (Xie, 2016) in addition to sensitise them about the risk of purchasing goods. Shopping bot is another source that aggregates data from many buyers and facilitates the information search. As Andersen Consulting (Bargain-Finder) establishes the first shopping bot, there is a tremendous growth of shopping bots (Iyer and Pazgal, 2016). These internet shopping agents (ISA) do the legwork of accepting specific product queries from consumers; search various online stores that deal with the product and show price and availability details. In the Indian contexts, few popular websites such as Carwale.com, booking.com and trivago.com function as ISA.

Despite the firm's effort and facilitating conditions, lack of trust is an important reason that prevents consumers' online shopping. Often, consumers use seller reputation as a proxy to overcome this risk and consider it as a very important factor while going for online purchases even though shopping website's usability does not influence the consumers' choice (Jun and Jaafar, 2011). In addition to the reputation factor, sellers try to build trust in online shopping by providing insurance policies or guarantees, security and privacy seal, clear picture of products and contact details (Huseynov and Yildirim, 2014). Research from Chinese context shows that the bankers are facilitating the online buying process by providing digital certificates for the security of transactions in addition to cash on delivery (COD) (Jun and Jaafar, 2011).

In a research work on the attitude of online sellers, researchers show that the customers expect a positive and vibrant seller as a source to buy the products, and the purchase intention improves if the e-retailer exhibit positivity through their actions (Hasbullah et al., 2016). Product presentation in an animated graphical mode also increases the level of consumer satisfaction with the e-retailers. Better product presentation improves the level of positive attitude and intention to buy the product online (Huseynov and Yildirim, 2014).

Researchers have addressed various online reviews' message characteristics and their role in the purchase decision process. A study on topic modelling of reviews of experience goods proves that objective information is considered as more helpful than subjective information in the reviews (Heng et al., 2018). Research work on star ratings proves that review message valence has a positive impact on the star ratings (Yoon et al., 2019). There are also evidences that star rating influences purchase decisions (Wang et al., 2015), product liking (Moe and Trusov, 2011), the quantum of sales (Chiu et al., 2019; Arbelles et al., 2020) and even post-purchase behaviour (Chua and Banerjee, 2016). Studies on length of the review conclude that ideal length is 3-5 lines (Hernández-Ortega, 2020); longer reviews are from high-ranked reviewers (Baek et al., 2012), and length affects perceived helpfulness (Ryan and Alexander, 2010) and the use of the review (Heng et al., 2018).

However, very little efforts have made until recently to understand the distribution characteristics of online consumer reviews. Unless a reviewer knows the distribution 
characteristics of online reviews of a particular retail firm, he cannot use online consumer reviews effectively in the decision-making process. To address this research gap, we have collected online product reviews from Amazon (24704 reviews) and Flipkart (17753 reviews) for 11 product categories (experience goods) and 34 brands. We choose brands that are commonly dealt with by both the retailers to control brand-specific biases in the evaluation, and 42,457 online reviews are gathered.

To understand the distribution characteristics of online reviews, we analyse the star ratings of reviews for the brands chosen. The brand reviews are then aggregated to each product. Then we have compared the variations in star ratings across the products for both the e-retailers. We analyse the data through correspondence analysis to develop perceptual maps to bring out the distribution characteristics of online reviews of the selected products by the retailers. This result will provide insights for the consumers on the e-retailers communication strategies of managing online reviews, preparing oneself to understand the distribution of information characteristics and managing information asymmetry in online review contents while making decisions.

\section{Grounding theories}

To address the distribution characteristics of online reviews, we consider four important grounding theories and relate them to the online retail environment to ascertain their significance.

(1) Signaling theory: Research work on signaling theory suggests how information asymmetry shall be reduced between two stakeholders in the process (Connelly et al., 2011). The first kind of information asymmetry occurs because an individual likes to communicate a piece of information to another person, whereas the other person wishes not to have that. Few instances, information asymmetry occurs when some private information kept confidential by one person that could be more useful to another person to arrive better decision if he has that piece of information. The third type of asymmetry is information about intent and information about quality. When one party is concerned about another person's behaviour or intentions, intent asymmetry occurs. On other hand, when one party is not fully aware of the characteristics of the second party, information asymmetry on quality occurs. Any online e-retail firm encounters these information asymmetrical conditions and develop appropriate signalling mechanisms to address these conditions. The retailers should consider presenting product information or online review in such a way to resolve the information asymmetry.

(2) Cue theory: Studies have addressed impersonal buying-selling conditions (buying by mail) and related apprehensions, during early the 1970s. One of the earlier study results shows that a buyer faces uncertainty because of his inability to examine the items and to interact with the seller physically (Spence $e$ t al., 1970) leading to avoid buying products through impersonal methods. Pioneering work on speed of visual processing suggests that recognition of familiar objects or pictures is instantaneous, but measuring the processing time is very difficult and proved to be very shorter (Thorpe et al., 1996). From the signaling theory and cue theory perspective, when a customer visits an unknown website to make purchases, he has to decide the trustworthiness of the retailers based on the cues presented or decode information signals presented in the website (Wang et al., 2004). The eretailers have very short duration to sequence and present cues in the 
communication so that, within the limited time-slot, a consumer develops trust and decide purchase.

(3) Information Integration Theory: The Information Integration Theory of Anderson (1981) describes that consumer's new beliefs and attitudes are formed when he receives a piece of stimulus information, interpret them, evaluate and integrate with existing attitudes and beliefs (Simonin and Ruth, 1998). The retail firm should address the information need of a new visitor or an existing customer so that a new belief is positively generated or append the existing beliefs. A popular application of this theory is found in television commercials use, where the marketers try to engage consumers by repeating the ads and modify the existing beliefs.

(4) Theory of Deception Detection: The Theory of Deception Detection concludes that to detect the deception content, a consumer must have domain expertise skills to identify the cues presented in a communication (Xiao and Benbasat, 2011). Particularly, in an impersonal, online consumer transaction processes, the firm has to ensure that the consumer should feel that no cues of deceptive practices are sensed by him.

Thus, these theories have relevance in the consumer's purchase decision process and the retailer's information presentation strategy. Marketers shall ensure their communication has appropriate content (Signaling Theory), presentation of cues (Cue Theory), capable enough to form new beliefs and attitudes (Information Integration Theory) in such a way that the customers do not feel of any deceptive content (Theory of Deception Detection) in the information presented and develop initial trust with the online retailer.

\section{Review of earlier studies}

Online retailers should understand the antecedents and behaviour of online consumers and focus on a stable relationship and trust-building activities (Wang et al., 2004). This will resolve to break the barrier of "relational exchanges", which involves sharing of personal information and money by the consumers. Research results show a very high degree of social influence in online buying. The consumers accept the experiences of trusted persons during their online buying adoption, and this behaviour facilitates them to do a similar online buying activity (Hasbullah et al., 2016). Thus to complete the online purchases, they are searching for product details from more number of trusted buyers. Online feedbacks act as a key parameter to trust the sellers and to build sellers' reputation. This reputation is capable of influencing the buyers to pay a premium price for sellers' offerings ( $\mathrm{Ba}$ and Pavlou, 2002).

Research results from Nigerian context show that convenience, time-saving and access to internet facilitate online shopping, whereas they express concerns for network instability and payment safety for online transactions (Oresanya and Oresanya, 2016). Marketers expect to highlight positive features such as convenience, the efficiency of online shopping than negative features such as efforts or impersonality (Yang and Lester, 2004). Among the many components of online review content, we consider the star rating for our research purpose. Researchers argue that star rating is an important cue for experience goods than search goods, and helpfulness of a review is improved by the star ratings (Singh et al., 2016). This graphic cue content passes the information faster than the review content.

Due to the significance of star rating in online reviews, it is a focal point of research for many years. Researchers produce mixed results on star ratings; research work on star rating proves incongruence between message content and star rating (Baek et al., 2012). Researchers show that there is a stronger relationship between the star rating and positive 
reviews than longer reviews (Ghasemaghaei et al., 2018). A research outcome shows that higher star-rated reviews are considered as very useful reviews by the consumers (Liu and Park, 2015). To broaden the understanding on star rating, another study on star rating proves that the products with an average star rating in the range of 4.5-5 are less likely to result in sales than those products rating falls in the range of 4-4.5. The researchers debate that consumer thinks that such reviews are too good to be true and hence discount the content in the purchase decision (Maslowska et al., 2016; Anderson et al., 2015). However, it is also argued that as the negative reviews contain new information presented in different ways, the reviewers are more influenced by the content (Lee, 2013).

An experiment on the eWOM proves that the website and message credibility get damaged in the long run if all the messages are positive (Sun-Jae Doh and Hwang, 2009). Extremely high and low star ratings are considered as less helpful than those reviews with moderate star ratings (Mudambi and Schuff, 2010). Contradictory to this finding, research work findings show that higher review rating automatically generates more number of helpfulness votes (Korfiatis et al., 2012). Higher star ratings are outcomes of the favourable post-purchase consumption experience; the reviewers give more weightage to the positive reviews than negative contents (Chua and Banerjee, 2016). It is also argued that 4-star and 5star reviews contain more emotional contents than other star-rated reviews (Ullah et al., 2016).

Thus, the earlier studies have addressed the significance of various online review parameters and their relationships in the consumer purchase process. However, to strengthen the decision process, understanding the characteristics of information cues is an antecedent condition to take various purchase decisions. We address the gap by developing perceptual maps for the retailers (Amazon and Flipkart) to bring out the association between star rating and product category to understand the distribution characteristics of star ratings in online reviews. This process will help the consumers to decode the information integration strategies followed by the e-retail firms in the review ratings.

\section{Methodology}

Firstly, we operationalise the distribution characteristics of the star rating. We describe the distribution characteristics in terms of "percentage of reviews that are having one-star or two-star" etc., for a specific product category considered in a seller's website. To bring out distribution characteristics, we consider the "variation of star ratings (percentages of star ratings) for different product categories". For example, seller-1 website may carry reviews with more number of 5-star ratings than seller-2, and there is a higher likelihood to see a 5star rating than a 1-star rated review in few products and vice versa. To understand this association, we compare star ratings in online reviews across the products. We collect sample reviews from two popular online retail firms, Amazon and Flipkart websites, to address the association. The association is inferred from developing nominalmultidimensional scales, also known as correspondence analysis.

To develop perceptual maps to depict the association between star ratings and product categories, for the experience goods, 11 products are chosen. Within a product category, two or three brands, which are commonly available in both the shelves, are picked. Using Python programming, we collected the customers' online reviews from Amazon and Flipkart websites. For each review, we collected the star rating assigned by the reviewer for the analysis purpose. For developing the nominal-multidimensional scales, we store the respective product category as an additional variable in the data set for each review. Out of the 42,457 sample reviews taken for the study, 58\% (24,704 reviews) are taken from Amazon 
and $42 \%$ of the remaining reviews are (17,753 reviews) from Flipkart. Table 1 contains the list of brands used in the study and sample size of each product category for the retailers.

Specifically, we analyse the distribution of star rating across the product categories for Amazon and Flipkart; hence, this study can be considered as a descriptive research work (Cooper and Schindler, 2002).

\subsection{Pre-processing data}

Preprocessing of the text data is the starting point of any text analysis procedure. Through the R-Programing and the R-Studio, we use plugins such as wordcloud, wordcloud2, tm and gsub command to preprocess the data. As per the earlier literature guidelines, the preprocessing is done (Al-Otaibi et al., 2018; Gaikar and Marakarkandy, 2015). In this stage, various tasks such as the removal of punctuations, special characters in a review, numbers and symbols, lowercasing the words and removal of stem words and blank spaces are carried out. Then for each review, we identify the star rating, product category and e-retailer name and add them back to the data set for further analyses.

\section{Results}

To understand the distribution characteristics and information strategies followed by the eretail firms, we try to find out the association between star ratings and product categories through correspondence analysis.

This analysis will bring out the relationship between two selected variables (product category-nominal scaled and star rating-interval scaled) by developing a low-dimensional map and describing the relationships between the categories of each variable. The distance between any two category points in the two-dimensional space reflects the relationship between the categories. If two categories are plotted closer in the space, it reflects the closeness of the categories (Figure 1).

\begin{tabular}{|c|c|c|c|c|}
\hline \multirow[b]{2}{*}{ Product category } & \multicolumn{2}{|c|}{ Amazon review counts } & \multicolumn{2}{|c|}{ Flipkart review counts } \\
\hline & Frequency & $(\%)$ & Frequency & $(\%)$ \\
\hline Beverages & 7,035 & 16.6 & 2,346 & 13.2 \\
\hline Biscuit & 2,846 & 6.7 & 312 & 1.8 \\
\hline Floor clean & 3,284 & 7.7 & 354 & 2.0 \\
\hline Haircare & 6,691 & 15.8 & 3,982 & 22.4 \\
\hline Health drink & 3,994 & 9.4 & 704 & 4.0 \\
\hline Juice & 1,938 & 4.6 & 1,331 & 7.5 \\
\hline Paste & 2,239 & 5.3 & 1,009 & 5.7 \\
\hline Shampoo & 2,441 & 5.7 & 1,679 & 9.5 \\
\hline Soap & 6,507 & 15.3 & 4,346 & 24.5 \\
\hline Talcum powder & 2,449 & 5.8 & 1,282 & 7.2 \\
\hline Washing & 3,033 & 7.1 & 408 & 2.3 \\
\hline Total & 42,457 & 100.0 & 17,753 & 100.0 \\
\hline Brands & $\begin{array}{l}\text { Ariel, Bournvita, } \\
\text { Toothpaste Max } \\
\text { Head and Shoul } \\
\text { Talk Pantene Adv } \\
\text { flower Fragrance, } \\
\text { WaterTangJuice } \\
\text { Santoor Sanda }\end{array}$ & $\begin{array}{l}\text { Colgate I } \\
\text { antasy, } \\
\text { s, IFB W } \\
\text { Fall, Pec } \\
\text { al,Real A } \\
\text { n, Lizol, } \\
\text { eric, Taj }\end{array}$ & $\begin{array}{l}\text { paste, Colgat } \\
\text { Beauty Bathi } \\
\text { der, KrackJac } \\
\text { Aloe Vera, Pe } \\
\text { abel Tea, Rin, } \\
\text { Parachute A } \\
\text { Tata God Te }\end{array}$ & $\begin{array}{l}\text { th, Colgate } \\
\text { Hair Cream, } \\
\text { Jivea Musk } \\
\text { ND'S Dream } \\
\text { asilk Coconut } \\
\text { n Hair Oil, } \\
\text { ir Cream }\end{array}$ \\
\hline
\end{tabular}

Star ratings in online consumer reviews

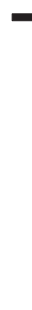


Figure 1.

Star rating and product category association

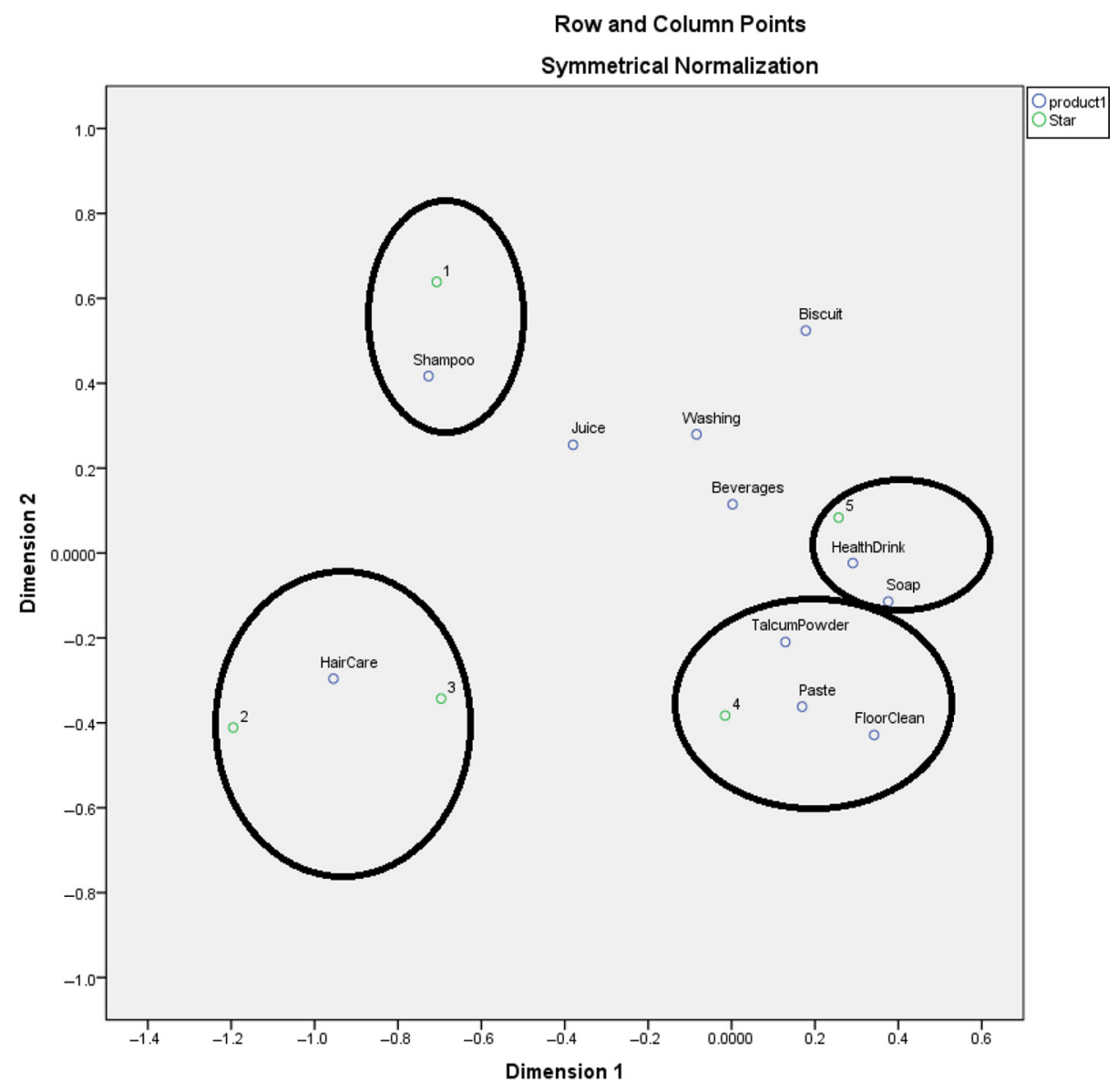

\section{Source: Amazon}

The correspondence analysis results related to Amazon is summarised in Tables 2 and 3. The two-dimensional solution is retained for further discussions. Two dimensions together account for $98 \%$ of the inertia, and Dimension- 1 accounts for $77 \%$, and Dimension-2 accounts for $21 \%$ of the inertia. As far as product categories are concerned, haircare, health care, shampoo, soap and juice largely represented by Dimension-1, and beverages and biscuits are largely represented by Dimension-2. Distribution of star ratings, concerned as 4star ratings, is largely represented by Dimension-2, and the remaining star ratings are represented by Dimension-1.

The correspondence analysis results related to Flipkart is summarised in Tables 4 and 5 . Two-dimensional solution is retained for further discussions (Figure 2).

Two dimensions together account for $96 \%$ of the inertia, and Dimension- 1 accounts for $90 \%$, and Dimension- 2 accounts for $6 \%$ of the inertia. As far as product categories are concerned, floor clean, haircare, juice, paste, shampoo, soaps and washing powder are largely represented by Dimension-1. Except 4-star ratings, the remaining star ratings are represented by Dimension-1. 


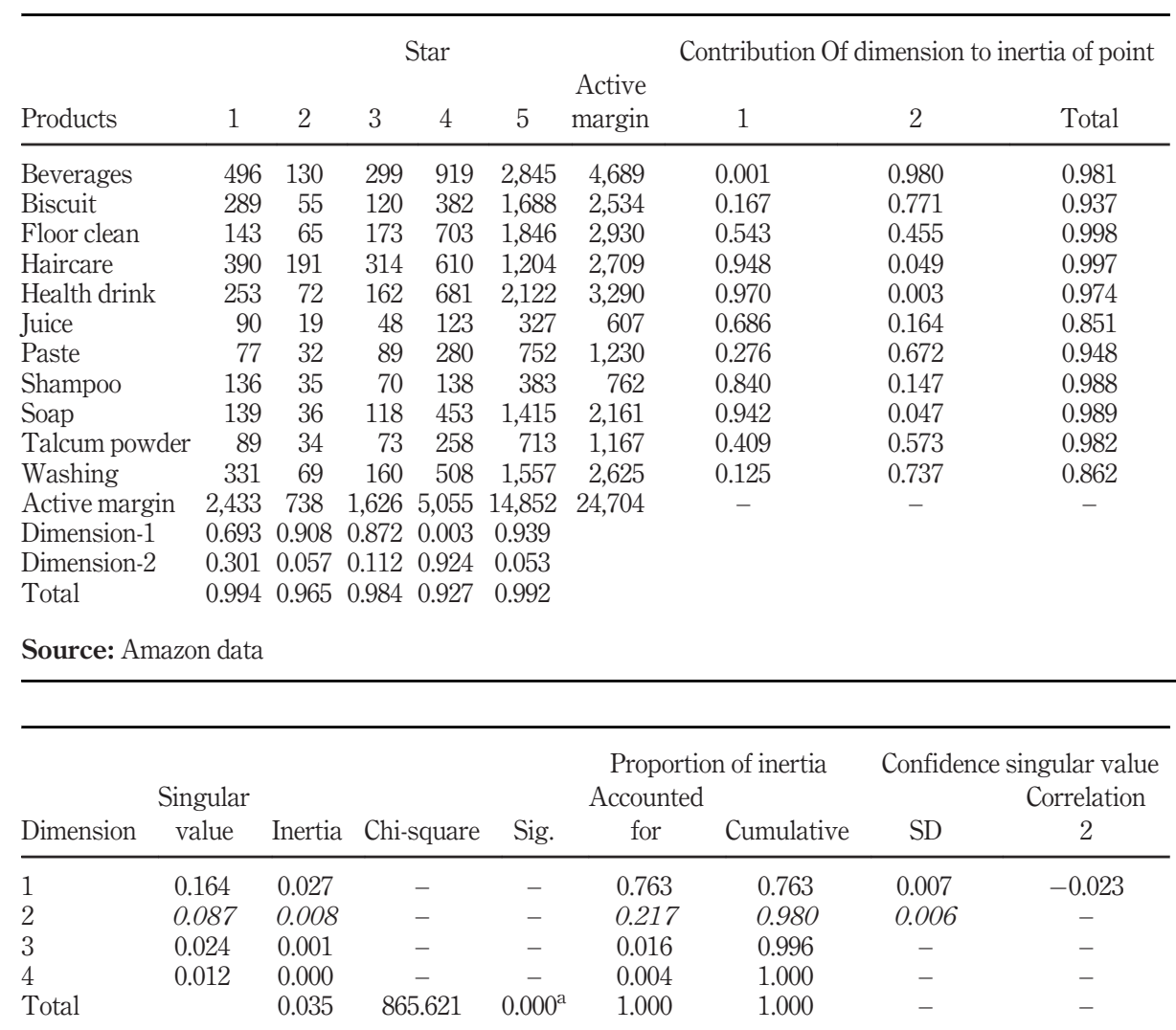

Notes: ${ }^{\mathrm{a}} 40$ degrees of freedom; italic data conveys the proportion of variance explained by the analysis for Amazon data

Source: Amazon data

Table 3. Fitness measures

\section{Discussion}

Few research works have addressed the significance of content management strategies by the firms and the relationships between content type and purchase decisions. From the managerial point of view, online retail firms have to decide the amount of negative content versus positive content to be presented on the website. On the other hand, to make online purchases, the consumers should aware of the positive and negative feedbacks about the product through online reviews. In this research work, we address these two research gaps by exploring the association among star ratings and product categories and information asymmetry in online reviews between the retailers.

Perceptual map related to Amazon reviews indicates the communication strategy followed by Amazon. The product website contains relatively more number of 1-star and 2star reviews than Flipkart product site. Amazon website has nearly 13\% of negative starrated reviews, whereas Flipkart website contains only $6.5 \%$ of negative star-rated reviews. Moreover, distribution of 5-star ratings in Amazon site is in the range of 50\%-66\%, whereas for Flipkart website, 5 -star rating distribution is in the range of $57 \%-73 \%$ for the 11 


\begin{tabular}{|c|c|c|c|c|c|c|c|c|c|c|}
\hline \multirow[t]{2}{*}{$\begin{array}{l}\text { XJM } \\
18,2\end{array}$} & \multirow[b]{2}{*}{ Products } & \multirow[b]{2}{*}{1} & \multirow[b]{2}{*}{2} & \multirow[b]{2}{*}{3} & \multirow{2}{*}{$\begin{array}{c}\text { Star } \\
4\end{array}$} & \multirow[b]{2}{*}{5} & \multirow[b]{2}{*}{ Active Margin } & \multicolumn{3}{|c|}{$\begin{array}{l}\text { Contribution Of dimension to } \\
\text { inertia of point }\end{array}$} \\
\hline & & & & & & & & 1 & 2 & Total \\
\hline \multirow{15}{*}{164} & Beverages & 99 & 42 & 130 & 472 & 1,603 & 2,346 & 0.387 & 0.177 & 0.563 \\
\hline & Biscuit & 12 & 1 & 26 & 51 & 222 & 312 & 0.217 & 0.198 & 0.415 \\
\hline & Floor clean & 44 & 4 & 32 & 65 & 209 & 354 & 0.654 & 0.298 & 0.952 \\
\hline & Haircare & 342 & 135 & 382 & 856 & 2,267 & 3,982 & 0.992 & 0.007 & 0.999 \\
\hline & Health drink & 27 & 5 & 34 & 128 & 510 & 704 & 0.554 & 0.409 & 0.963 \\
\hline & Juice & 43 & 22 & 84 & 270 & 912 & 1,331 & 0.892 & 0.002 & 0.894 \\
\hline & Paste & 28 & 8 & 53 & 225 & 695 & 1,009 & 0.876 & 0.015 & 0.892 \\
\hline & Shampoo & 90 & 38 & 150 & 357 & 1,044 & 1,679 & 0.740 & 0.156 & 0.896 \\
\hline & Soap & 55 & 32 & 247 & 936 & 3,076 & 4,346 & 0.987 & 0.007 & 0.994 \\
\hline & Talcum powde & ar 37 & 21 & 99 & 271 & 854 & 1,282 & 0.547 & 0.324 & 0.871 \\
\hline & Washing & 32 & 9 & 30 & 86 & 251 & 408 & 0.845 & 0.115 & 0.960 \\
\hline & Active margin & 809 & 317 & 1,267 & 3,717 & 1,1643 & 17,753 & - & - & - \\
\hline & Dimension-1 & 0.96 & 0.835 & $5 \quad 0.804$ & $4 \quad 0.002$ & 0.954 & - & - & - & - \\
\hline & Dimension-2 & 0.04 & 0.1 & 0.077 & 0.537 & 0.035 & - & - & - & - \\
\hline & Total & 0.999 & $9 \quad 0.934$ & 0.881 & 0.539 & 0.989 & - & - & - & - \\
\hline
\end{tabular}

Correspondence table Source: Flipkart data

Proportion of inertia Confidence singular value Correlation Dimension Singular value Inertia Chi-square Sig. Accounted for CumulativeStandard deviation 2

\begin{tabular}{lcccccccc}
\hline 1 & 0.174 & 0.030 & - & - & 0.901 & 0.901 & 0.008 & 0.039 \\
2 & 0.046 & 0.002 & - & - & 0.063 & 0.964 & 0.008 & - \\
3 & 0.029 & 0.001 & - & - & 0.024 & 0.988 & - & - \\
4 & 0.020 & 0.000 & - & - & 0.012 & 1.000 & - & - \\
Total & & 0.034 & 598.867 & $0.000^{\mathrm{a}}$ & 1.000 & 1.000 & - & -
\end{tabular}

Table 5.

Notes: ${ }^{\text {a }} 40$ degrees of freedom; italic data conveys the proportion of variance explained by the analysis for Flipkart Data

Fitness measures $\quad$ Source: Flipkart data

products chosen. This distribution suggests that Amazon and Flipkart use two distinct communication strategies.

Further, if we notice the association of star rating and product categories, relatively more number of 1-star and 2-star review data from Amazon has closer association with categories such as shampoo and haircare products, whereas no product category is relatively closer to 1-star or 2-star ratings in the Flipkart reviews. Thus, Amazon allows few categories perceived to be poor, whereas Flipkart does not allow forming such opinions.

Positive reviews and negative reviews are equally considered in the consumer purchase decisions and a survey of online consumers shows mixed evidences on type reviews used by the consumers. Nearly $90 \%$ of them used positive reviews and $86 \%$ of them used negative reviews before making the decisions (Dimensional-Research, 2013). Researchers prove that quantum of positive reviews affect positively the consumer-buying behaviour, whereas negative reviews create negative impact in the purchase process (Mo et al., 2015). Further, references from prospect theory suggests that people give more importance to experience of loss than profits or gain associated with an outcome (Park and Nicolau, 2015). Thus, 


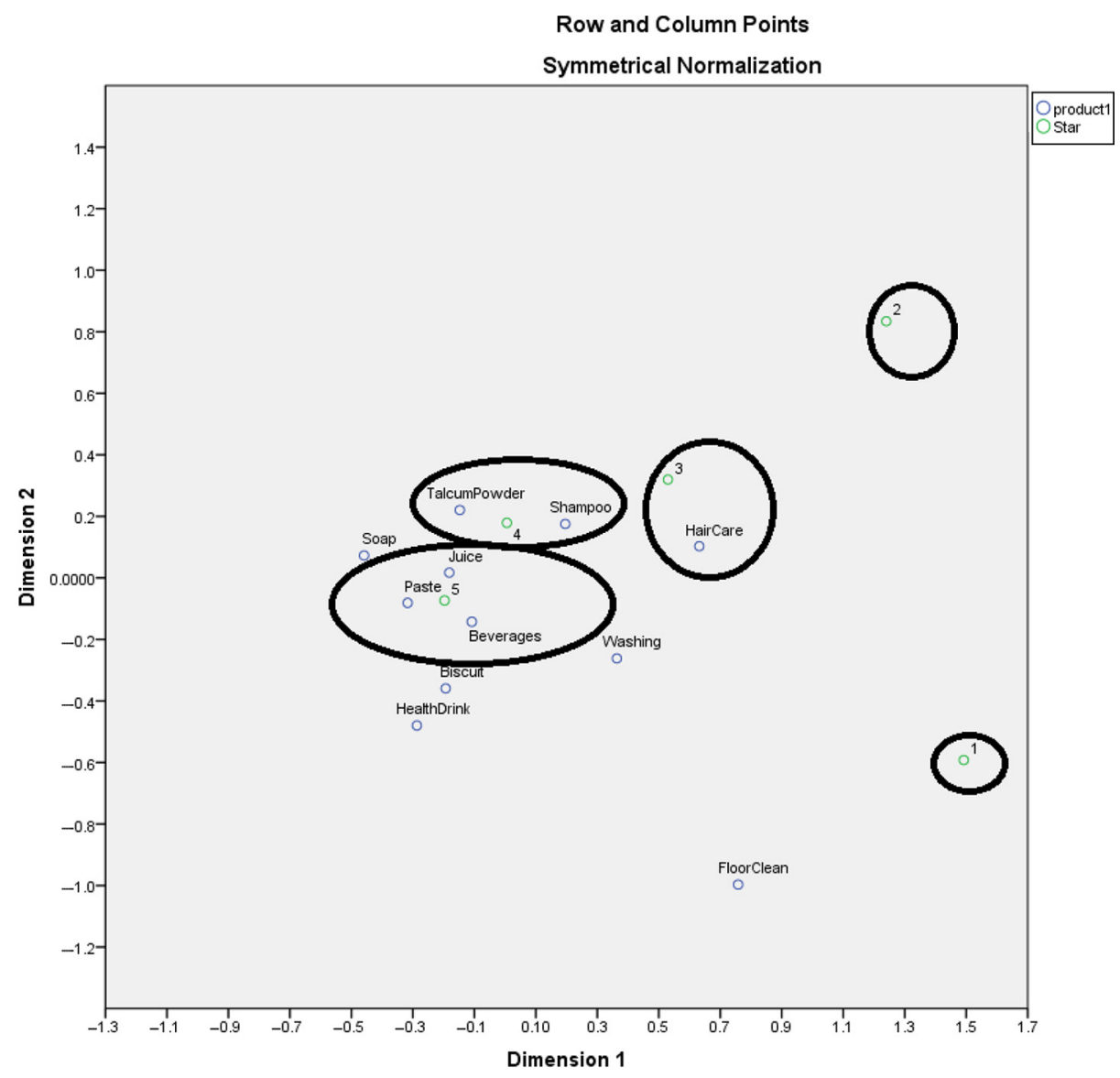

Star ratings in online consumer reviews 165

\section{Source: Flipkart}

Amazon decides to present relatively more amount of negative reviews and reviews with lower star ratings.

Earlier studies in online consumer reviews confirm that incidences of positive word-ofmouth are higher than negative word-of-mouth communications (Cheung and Lee, 2012), and shoppers exhibit positivity bias by generally preferring positive reviews to negative reviews (Weathers et al., 2015). It is also observed that 5-star ratings contains more number of emotional words than other star ratings (Ullah et al., 2016), and consumers who see more number of positive ratings suspect about the reviews (Maslowska et al., 2016); however, Flipkart decides to use more amount of positive contents and higher star ratings only. Thus, the two e-retailers use very distinct communication strategies, and, hence, the distribution of star ratings is following different distribution patterns.

\section{Conclusion}

Types of content (positive or negative) and presentation styles are addressed rarely in the online consumer behaviour researches. This research work has addressed this gap, by 
establishing the perceptual maps and information strategies followed by two giant marketers in the subcontinent. A study by Bright Local, a US-based consulting firms proves that $79 \%$ of the respondents trust the online reviews as equivalent as a personal recommendation from their neighbours or friends (Bright-Local, 2013). Even though positive reviews have an upper hand in the purchase decisions, consumers consider those reviews that are directly clarify an issue and other positive reviews are not given any importance in the purchase decisions (Inés López-López and Parra, 2016). Hence, presenting content, creating awareness and reinforcement are important goals that shape the communication strategies of the firms. By seeing the star ratings, consumers alter their attitude towards products, and these ratings play a significant role in the learning process of the consumers (Mo et al., 2015).

Hence, from the results, we bring a two-sided suggestion for the retailers and the consumers. The retailers have to deice quantum of extreme reviews and decide the distribution pattern for star ratings in the website. From the consumer's view, one should know the distribution characteristics of the review component very well to make better decisions. Moreover, we prove the presence of the information asymmetry in the online review system by showing the variations in star ratings across the products and for the retail firms.

\section{Managerial implications}

The firms should decide the trade-off between positive and negative contents and cues presented in the product website. Few researchers emphasise the significance of negative evaluations and star ratings. A research work by Lee(2013) shows that due to novelty, new information and critics, the consumers are highly influenced by the review content of negative reviews (Lee, 2013). Another research work proves that consumers suspect a positive review or over-the-top review as fake ones and think that commercial sources would have published them (Inés López-López and Parra, 2016). On the other hand, researchers prove that strong positive and medium reviews significantly influence the purchase decisions of the consumers but not the negative ones (Floh et al., 2013). The research work gives insights for the managers to position product categories and alter the positioning strategies based on consumer insights. This will help the firms to manage product categories effectively by leveraging the information from a competing firm.

Research related to cue use confirms that reviewers use cues, which are easily observable and assessable with confidence. These cues are most influential in the purchase process than other cues analysed by him (Wells et al., 2011). Amazon and Flipkart use star ratings as a distinct cue in their communication strategies. It is very clear from the results that Amazon and Flipkart use distinct strategies to position themselves through the online consumer reviews.

Qualitative and quantitative research results prove the social interactions among consumers, where they see others' opinions while positing their reviews and that is evidenced through shared vocabularies and jargons in the reviews (Yoon et al., 2019). Hence, the marketers have to decide a clear communication strategy for the content to be presented - to show more or less positive content.

\section{Limitations and future research directions}

On many occasions, evaluation of experience goods attributes are temporal, which keep changing based on product consumptions and expectations. Attribute-related information might not be available for comparisons for consumers even in the post-consumption stage. Moreover, the website privacy policy does not allow the researchers to access the reviewer's product adoption; that is, the first time user versus longer association. Thus, one cannot distinguish whether the reviews are posted based on their first time experience or repeat consumption experiences. Researchers have 
established the significance of demographic variables in the consumption of fast-moving consumer goods; because of access restriction of demographic details, we did not analyse the role of demographic details and their influence.

By including the mood of the consumers, future researches can bring temporal variables influence in the reviews. From the profile of the users, it is possible to identify consumerbuying segments and review characteristics may be analysed across the buyer segments. The brand level analysis will provide further insights into the distribution of consumers review characteristics.

Star ratings in online consumer reviews

\section{References}

Al-Otaibi, S., Alnassar, A., Alshahrani, A., Al-Mubarak, A., Albugami, S., Almutiri, N. and Albugami, A. (2018), "Customer satisfaction measurement using sentiment analysis", International Journal of Advanced Computer Science and Applications, Vol. 9 No. 2, pp. 106-117.

Anderson, K. Reifenberger, D. and Neil, T.O. (2015), "Assessing the impact of ratings and reviews on eCommerce performance", Profitero.

Arbelles, K.D., Berry, P. and Theyyil, A. (2020), "Electronic word-of-mouth marketing on amazon: exploring how and to what extent Amazon reviews affect sales", The McMaster Journal of Communication, Vol. 12, pp. 50-79.

Ba, S. and Pavlou, P.A. (2002), "Evidence of the effect of trust building technology in electronic markets: price premiums and buyer behavior", MIS Quarterly, Vol. 26 No. 3, pp. 1-26, available at: https://doi.org/ $10.2307 / 4132332$

Baek, H., Ahn, J. and Choi, Y. (2012), "Helpfulness of online consumer reviews: readers' objectives and review cues", International Journal of Electronic Commerce, Vol. 17 No. 2, pp. 99-126, available at: https://doi.org/10.2753/JEC1086-4415170204

Bright-Local (2013), "Local consumer review survey 2013”.

Cheung, C.M.K. and Lee, M.K.O. (2012), "What drives consumers to spread electronic word of mouth in online consumer-opinion platforms", Decision Support Systems, Vol. 53 No. 1, pp. 218-225, available at: https://doi.org/10.1016/j.dss.2012.01.015

Chiu, Y.L., Chen, K.H., Wang, J.N. and Hsu, Y.T. (2019), "The impact of online movie word-of-mouth on consumer choice: a comparison of American and Chinese consumers", International Marketing Review, Vol. 36 No. 6, pp. 996-1025, available at: https://doi.org/10.1108/IMR-06-2018-0190

Chua, A.Y.K. and Banerjee, S. (2016), "Helpfulness of user-generated reviews as a function of review sentiment, product type and information quality", Computers in Human Behavior, Vol. 54, pp. 547-554, available at: https://doi.org/10.1016/j.chb.2015.08.057

Connelly, B.L., Certo, S.T., Ireland, R.D. and Reutzel, C.R. (2011), "Signaling theory: a review and assessment", Journal of Management, Vol. 37 No. 1, pp. 39-67, available at: https://doi.org/10.1177/0149206310388419

Cooper, D.R. and Schindler, P.S. (2002), Business Research Methods, Tata McGraw-Hill, New Delhi.

Dimensional-Research (2013), "Customer service and business results: a survey of customer service from mid-size companies".

Floh, A., Koller, M. and Zauner, A. (2013), "Taking a deeper look at online reviews: the asymmetric effect of valence intensity on shopping behaviour", Journal of Marketing Management, Vol. 29 No. 5-6, pp. 646-670, available at: https://doi.org/10.1080/0267257X.2013.776620

Gaikar, D. and Marakarkandy, B. (2015), "Product sales prediction based on sentiment analysis using Twitter data", International Journal of Computer Science and Information Technologies, Vol. 6 No. 3, pp. 2303-2313.

Ghasemaghaei, M., Eslami, S.P., Deal, K. and Hassanein, K. (2018), "Reviews' length and sentiment as correlates of online reviews' ratings", Internet Research, Vol. 28 No. 3, pp. 544-563, available at: https://doi.org/10.1108/IntR-12-2016-0394 
Hasbullah, N.A., Osman, A., Abdullah, S., Salahuddin, S.N., Ramlee, N.F. and Soha, H.M. (2016), "The relationship of attitude, subjective norm and website usability on consumer intention to purchase online: an evidence of Malaysian youth*”, Procedia Economics and Finance, Vol. 35, pp. 493-502, available at: https://doi.org/10.1016/S2212-5671(16)00061-7

Heng, Y., Gao, Z., Jiang, Y. and Chen, X. (2018), "Exploring hidden factors behind online food shopping from Amazon reviews: a topic mining approach", Journal of Retailing and Consumer Services, Vol. 42, pp. 161-168, available at: https://doi.org/10.1016/j. jretconser.2018.02.006

Hernández-Ortega, B. (2020), "When the performance comes into play: the influence of positive online consumer reviews on individuals' post-consumption responses", Journal of Business Research, Vol. 113, pp. 422-435, available at: https://doi.org/10.1016/j. jbusres.2019.08.026

Huseynov, F. and Yildirim, S.O. (2014), "Internet users' attitudes toward business-to-consumer online shopping: a survey", Information Development, Vol. 32 No. 3, pp. 1-14, available at: https://doi. org/10.1177/0266666914554812

Inés López-López, A. and Parra, J.F. (2016), "Is a most helpful eWOM review really helpful? The impact of conflicting aggregate valence and consumer's goals on product attitude", Internet Research, Vol. 26, available at: https://doi.org/10.1108/IntR-07-2014-0176

Iyer, G. and Pazgal, A. (2016), "Internet shopping agents: virtual co-location and competition", Marketing Science, Vol. 22 No. 1, pp. 85-106.

Jun, G. and Jaafar, N.I. (2011), "A study on consumers' attitude towards online shopping in China", International Journal of Business and Social Science, Vol. 2 No. 22, pp. 122-132.

Korfiatis, N., García-Bariocanal, E. and Sánchez-Alonso, S. (2012), "Evaluating content quality and helpfulness of online product reviews: the interplay of review helpfulness vs review content", Electronic Commerce Research and Applications, Vol. 11 No. 3, pp. 205-217, available at: https:// doi.org/10.1016/j.elerap.2011.10.003

Lee, J. (2013), "What makes people read an online review? The relative effects of posting time and helpfulness on review readership”, Cyberpsychology, Behavior, and Social Networking, Vol. 16 No. 7, pp. 529-535, available at: https://doi.org/10.1089/cyber.2012.0417

Liu, Z. and Park, S. (2015), "What makes a useful online review? Implication for travel product websites", Tourism Management, Vol. 47, pp. 140-151, available at: https://doi.org/10.1016/j.tourman.2014.09.020

Maslowska, E., Malthouse, E.C. and Bernritter, S.F. (2016), "Too good to be true: the role of online reviews' features in probability to buy", International Journal of Adversiting, pp. 1-24, available at: https://doi.org/10.1080/02650487.2016.1195622

Mo, Z., Li, Y.-F. and Fan, P. (2015), "Effect of online reviews on consumer purchase behavior", Journal of Service Science and Management, Vol. 08 No. 03, pp. 419-424, available at: https:/doi.org/10.4236/ jssm.2015.83043

Moe, W.W. and Trusov, M. (2011), "The value of social dynamics in online product ratings forums", Journal of Marketing Research, Vol. 58, pp. 444-456.

Mudambi, S.M. and Schuff, D. (2010), "What makes a helpful online review? A study of customer reviews on amazon.com”, MIS Quarterly: Management Information Systems, Vol. 34 No. 1, pp. 185-200, available at: https://doi.org/10.2307/20721420

Oresanya, A. and Oresanya, T. (2016), "Attitude of students towards online shopping of agricultural products in selected tertiary institutions in Ogun state”, Journal of Agricultural Extension, Vol. 20 No. 1, pp. 121-131.

Park, S. and Nicolau, J.L. (2015), "Asymmetric effects of online consumer reviews", ANNALS oF TOURISM Research, Vol. 50, pp. 67-83, available at: https://doi.org/10.1016/j.annals.2014.10.007

Ryan, H. and Alexander, C. (2010), "The impact of product line extensions and consumer goals on the formation of price image", Journal of Marketing Research, Vol. 47 No. 1, pp. 51-62, available at: https://doi.org/ 10.1509/jmkr.47.1.51 
Simonin, B.L. and Ruth, J.A. (1998), "Is a company known by the company it keeps? Assessing the spillover effects of brand alliances on consumer brand attitudes", Journal of Marketing Research, Vol. 35 No. 1, pp. 30-42.

Singh, J.P., Irani, S., Rana, N.P., Dwivedi, Y.K., Saumya, S. and Kumar Roy, P. (2016), "Predicting the 'helpfulness' of online consumer reviews", Journal of Business Research, Vol. 70, pp. 1-10, available at: https://doi.org/10.1016/j.jbusres.2016.08.008

Spence, H.E., Engel, J.F. and Blackwell, R.D. (1970), "Perceived risk in mail-order and retail store", Journal of Marketing Research, Vol. 7 No. 3, pp. 364-369.

Star ratings in online consumer reviews

Sun-Jae Doh, M.S. and Hwang, J.-S. (2009), "How consumers evaluate eWOM (electronic word-of-mouth) messages", Cyberpsychology and Behavior, Vol. 12 No. 2, pp. 193-197, available at: https://oi.org/ 10.1089/cpb.2008.0109

Thorpe, S., Fize, D. and Marlot, C. (1996), "Speed of processing in the human visual system", Nature, Vol. 381 No. 6582, pp. 520-522.

Ullah, R., Amblee, N., Kim, W. and Lee, H. (2016), "From valence to emotions: exploring the distribution of emotions in online product reviews", Decision Support Systems, Vol. 81, pp. 41-53, available at: https://doi.org/10.1016/j.dss.2015.10.007

Wang, S., Cunningham, N.R. and Eastin, M.S. (2015), "The impact of eWOM message characteristics on the perceived effectiveness of online consumer reviews", Journal of Interactive Advertising, Vol. 15 No. 2, pp. 151-159, available at: https://doi.org/10.1080/ 15252019.2015.1091755

Wang, S., Beatty, S.E. and Foxx, W. (2004), "Signaling the trustworthiness of small online retailers", Journal of Interactive Marketing, Vol. 18 No. 1, pp. 53-69, available at: https://doi.org/10.1002/dir.10071

Weathers, D., Swain, S.D. and Grover, V. (2015), "Can online product reviews be more helpful? Examining characteristics of information content by product type", Decision Support Systems, Vol. 79, pp. 12-23, available at: https://doi.org/10.1016/j.dss.2015.07.009

Wells, J.D., Valacich, J.S. and Hess, T.J. (2011), "What signal are you sending? How website quality influences perceptions of product quality and purchase intentions", MIS Quarterly, Vol. 35 No. 2, pp. 1-24.

Xiao, B. and Benbasat, I. (2011), "Product-related deception in E-Commerce: a theoretical perspective", MIS Quarterly, Vol. 35 No. 1, pp. 169-195.

Xie, K. (2016), "Online consumer review factors affecting offline hotel popularity: evidence from Tripadvisor", available at: https://doi.org/10.1080/10548408.2015.1050538

Yang, B. and Lester, D. (2004), "Attitudes toward buying online", Cyberpsychology and Behavior, Vol. 7 No. 1, pp. 85-91, available at: https://doi.org/10.1089/109493104322820156

Yoon, Y., Kim, A.J., Kim, J. and Choi, J. (2019), "The effects of eWOM characteristics on consumer ratings: evidence from TripAdvisor.com", International Journal of Advertising, Vol. 38 No. 5, pp. 684-703, available at: https://doi.org/10.1080/02650487.2018.1541391

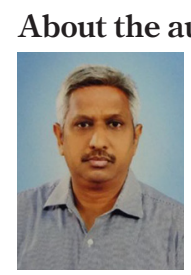

Dr R. Venkatesakumar is a Professor in the Department of Management Studies, Pondicherry University. He is having 21 years of Teaching and Research Experience and published 50 research papers and conference papers. A Graduate in Mathematics and research focus on Marketing, he is a trainer on SPSS/SAS/ R/AMOS/LISREL/PLS and Text Mining applications. He did his doctoral research on Consumer Purchase Decision Process in Rural Tamil Nadu, India. R. Venkatesakumar is the corresponding author and can be contacted at: venkatesh1316@gmail.com 
$\mathrm{XJM}$

18,2

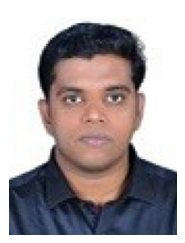

Sudhakar Vijayakumar is a full-time research scholar in the Department of Management Studies, Pondicherry University. Besides his engineering degree, he has done his MBA and pursuing doctoral research in the area of Text Analytics. He has developed software products for conducting online examinations, Prescriptive Analytics Modules and Text Scrappers. His research interest includes Text Mining and Cloud Computing.

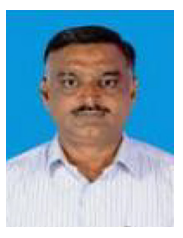

Dr S. Riasudeen is an Associate Professor in the Department of Management Studies, Pondicherry University. He is having 15 years of Industry and 15 years of Teaching and Research experience. He did his doctoral research in the area of Relationship of Group Factors with Individual Wellbeing. He edited three books and contributed six chapters in the edited volumes. He published 26 papers in various peer-reviewed journals and won best research paper awards. His research interests include Human Resources Management, Individual and Group Dynamics.

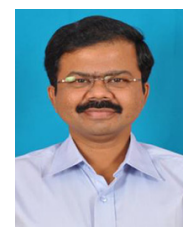

Dr S. Madhavan is a Professor in the Department of Management Studies, Manonmaniam Sundaranar University, Tirunelveli. He is having 21 years of Teaching and Research Experience and published 28 research papers and conference papers. A Graduate in Economics and research focus on International Finance, he is an active administrator, serves in a various position such as Syndicate Member, NAAC Accreditation Committee, IQAC, Director DD\&CE. He served as Chairperson for various MBA programmes and Research Programmes of the MS University.

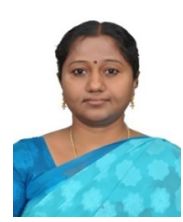

Dr B. Rajeswari is an Assistant Professor in the Department of Management Studies, Pondicherry University. She is having 20 years of Teaching and Research experience. She did her doctoral research in the area of Marketing. She edited two books and contributed ten chapters in the edited volumes. She published 30 papers in various peer-reviewed journals and won the best research paper awards. Her research interests include Organic, Green, Agricultural Marketing and Retail Management.

For instructions on how to order reprints of this article, please visit our website: 